2020-08-29

\title{
Development of Essential Oil Incorporated Active Film Based on Biodegradable Blends of Poly (Lactide)/Poly (Butylene Adipate-co-Terephthalate) for Food Packaging Application
}

\author{
Shubham Sharma \\ Technological University Dublin, d17127955@mytudublin.ie \\ Sandra Barkauskaite \\ Technological University Dublin \\ Swarna Jaiswal \\ Technological University Dublin, swarna.jaiswal@tudublin.ie
}

See next page for additional authors

Follow this and additional works at: https://arrow.tudublin.ie/schfsehart

Part of the Food Biotechnology Commons, Food Chemistry Commons, Food Microbiology Commons, Food Processing Commons, and the Other Food Science Commons

\section{Recommended Citation}

Sharma, S. (2020) Development of Essential Oil Incorporated Active Film Based on Biodegradable Blends of Poly (Lactide)/Poly (Butylene Adipate-co-Terephthalate) for Food Packaging Application,>i>Journal of Packaging Technology and Research 4(6) August 2020 DOI: 10.1007/s41783-020-00099-5

This Article is brought to you for free and open access by the School of Food Science and Environmental Health at ARROW@TU Dublin. It has been accepted for inclusion in Articles by an authorized administrator of ARROW@TU

Dublin. For more information, please contact arrow.admin@tudublin.ie, aisling.coyne@tudublin.ie, gerard.connolly@tudublin.ie.

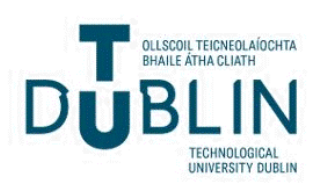


Authors

Shubham Sharma, Sandra Barkauskaite, Swarna Jaiswal, Brendan Duffy, and Amit Jaiswal 


\title{
Development of Essential Oil Incorporated Active Film Based on Biodegradable Blends of Poly (Lactide)/Poly (Butylene Adipate-co-Terephthalate) for Food Packaging Application
}

\author{
Shubham Sharma $^{1,2,3} \cdot$ Sandra Barkauskaite $^{1} \cdot$ Swarna Jaiswal $^{1}$ (D) $\cdot$ Brendan Duffy $^{3} \cdot$ Amit K. Jaiswal $^{1,2}$
}

Received: 25 May 2020 / Accepted: 14 August 2020 / Published online: 29 August 2020

(C) Indian Institute of Packaging 2020

\begin{abstract}
Active packaging improves the food safety and quality with the incorporation of certain additives such as antimicrobial agents. The PLA/PBAT films were prepared with two essential oils-eucalyptus oil and cinnamon oil of various concentrations (1\%, $5 \%$ and $10 \% \mathrm{w} / \mathrm{w}$ ) and characterised their optical and mechanical properties, surface hydrophobicity, chemical composition and antimicrobial activity. Cinnamon oil composite films were observed as thicker film $(88.88 \mu \mathrm{m})$ than the eucalyptus oil films $(54.46 \mu \mathrm{m})$. The highest UV-blocking properties were observed in cinnamon oil films. However, transparency and tensile properties of the cinnamon oil films decreases as the concentration increases. The tensile strength of the eucalyptus oil film decreased by $17 \%$, while for cinnamon by $42 \%$. The cinnamon oil $(10 \% \mathrm{w} / \mathrm{w})$ film showed $\approx 5 \%$ higher biofilm inhibition than eucalyptus oil $(10 \% \mathrm{w} / \mathrm{w})$. The PLA/PBAT-cinnamon oil films with potent antimicrobial and UV-blocking properties can be used in food packaging to improve the quality and increase the shelf-life of foods.
\end{abstract}

Keywords Active food packaging $\cdot$ Antimicrobial activity $\cdot$ Essential oils $\cdot$ Composite film $\cdot$ poly (lactide) $\cdot$ Poly (butylene adipate-co-terephthalate)

\section{Introduction}

The world population continues to grow each year, resulting in high demand for food to be produced together with food packaging. Food packaging can be considered as a passive barrier that protects the food from environmental factors such as ultraviolet light, oxygen, water vapour, pressure and heat [1]. Packaging also prolongs the shelf-life of food by protecting from chemical and microbiological contaminants and enables foods to be transported and stored safely. Current packaging technologies use either existing or novel

Swarna Jaiswal

swarna.jaiswal@tudublin.ie; swarna.jaiswal@ outlook.com

1 School of Food Science and Environmental Health, College of Sciences and Health, Technological University Dublin, City Campus, Grangegorman, Dublin 7, Ireland

2 Environmental Sustainability and Health Institute, Technological University Dublin, City Campus, Grangegorman, Dublin 7, Ireland

3 Centre for Research in Engineering and Surface Technology (CREST), FOCAS Institute, Technological University Dublin, City Campus, Kevin Street, Dublin 8, Ireland methods to maintain the quality of foods. Existing methods include vacuum packaging, controlled atmospheric packaging (CA) and modified atmospheric packaging (MAP), while intelligent and active packaging is considered as novel methods.

Over the past few years, traditional food packaging technologies are overtaken by more innovative approaches like active packaging. It protects and preserves food for an extended period, without any harm due to the external environment. Active packaging can be defined as a technology allowing to improve food safety and quality by the incorporation of certain additives such as essential oils into packaging film or within the packaging material. This type of packaging has the potential to minimize food waste because of its capability to preserve foods by scavenging, adsorbing, absorbing, emitting, releasing and removing gases and other materials. It also helps to maintain an appropriate temperature, moisture levels, microbial and quality control [2].

Even though the food packaging provides numerous beneficial properties, it harms the environment with a high volume of packaging material being produced, their short usage time, improper waste management and littering [3]. In addition to this, there is still a high production of packaging material 
containing petroleum derivatives that cause serious environmental problems. In order to prevent these issues, an alternative solution such as active packaging must be implemented.

Due to the rising interest in the use of essential oils as natural additives in biodegradable films for active food packaging, the present study was undertaken with the aim of determining the effect of essential oils on the structural, thermal and functional properties of composite films including the in vitro antibacterial activity of different essential oils against both gram-positive and gram-negative bacteria.

In the present study, solution casting method is used to incorporate essential oils (eucalyptus and cinnamon oil) as an antimicrobial agent in a PLA/PBAT (Poly (lactide)/poly (butylene adipate-co-terephthalate) blend film. To the best of the author's knowledge, this is the first report to incorporate essential oils at various concentrations in the PLA/ PBAT blend film. Effect of eucalyptus and cinnamon oil on the structural, functional and thermal properties of the composite films was studied.

\section{Materials and Methods}

\section{Materials}

Poly(lactide) (PLA, Synterra BF 2004; the weight-average molecular weight of $200 \mathrm{kDa}$ ) was purchased from Helian Polymer (Belfeld, Netherland). PBAT (poly (butylene adipate-co-terephthalate) (Ecoworld PBAT003; m.p. $110-120{ }^{\circ} \mathrm{C}$, the density of $1.26 \mathrm{~g} / \mathrm{cm}^{3}$ ) was obtained from Helian Polymer (Belfeld, Netherland). Ethanol was purchased from Merck KGaA (Germany) and chloroform was obtained from Sigma Aldrich (Ireland). Tryptic soy broth (TSB), Brain Heart Infusion Broth (BHI) and agar powder were purchased from Sigma Aldrich (Ireland). Foodborne pathogens such as Escherichia coli (NCTC 9001) and Staphylococcus aureus (ATCC 25923) were used. All of these strains were grown in the TSB and BHI agar media and stored at $4{ }^{\circ} \mathrm{C}$ before further testing.

\section{Essential Oils}

Liquid commercial preparations of essential oils were purchased from local a supermarket in Dublin (Ireland) namely eucalyptus oil, black pepper oil, turmeric oil, thyme oil, rosemary oil, fenugreek oil, lemon oil, neem oil, lavender oil and cinnamon oil.

\section{Screening of Essential Oils}

\section{Preparation of Bacterial Inoculum}

The antibacterial activity of essential oils was determined using two foodborne pathogenic bacteria such as $S$. aureus
(Gram positive) and E. coli (Gram negative). Bacterial inoculum of $10^{8} \mathrm{CFU} / \mathrm{ml}$ were prepared from the overnight subcultures. $100 \mu \mathrm{l}$ of the prepared suspension was transferred into $10 \mathrm{ml}$ nutrient broth in order to give a final concentration of $10^{6} \mathrm{CFU} / \mathrm{ml}$.

\section{Minimum Inhibitory Concentration}

The minimum inhibitory concentration (MIC) is the lowest concentration of antimicrobial agent that inhibits the visible growth of an organism [4]. The MIC of the essential oils was determined using the microtiter broth dilution method [5] and was performed in sterile, round-bottomed 96-well microtiter plates (Sarstedt, Inc, USA). $200 \mu$ of the essential oils was pipetted into the first row of microtiter plate and serially diluted with bacterial culture $\left(10^{6} \mathrm{CFU} / \mathrm{ml}\right)$. The bacterial culture without any oil was used as a control. The microtiter plate was incubated at $37^{\circ} \mathrm{C}$ for $18 \mathrm{~h}$ and optical density (OD) was measured at $600 \mathrm{~nm}$ every $30 \mathrm{~min}$.

\section{Percentage of Inhibition}

The antibacterial activity of the essential oils was determined by calculating their percentage inhibition of bacterial growth using the following equation:

$I \%=\frac{\left(C_{18}-C_{0}\right)+\left(T_{18}-T_{0}\right)}{\left(C_{18}-C_{0}\right)} \times 100$,

where $I$ is the percentage inhibition, $C_{18}$ is the OD at $600 \mathrm{~nm}$ of the positive control sample at $18 \mathrm{~h}, C_{0}$ is the OD at $600 \mathrm{~nm}$ of the positive control sample at $0 \mathrm{~h}, T_{18}$ is the OD at $600 \mathrm{~nm}$ of the sample at $18 \mathrm{~h}$ and $T_{0}$ is the OD at $600 \mathrm{~nm}$ of the sample at $0 \mathrm{~h}$.

\section{Minimum Bactericidal Concentration}

The minimum bactericidal concentration (MBC) is defined as the lowest concentration of the essential oil that kills $\geq 99.9 \%$ of start inoculum [6]. The MBC of each essential oil was determined by taking a small amount of inoculum from the broth dilutions of the MIC test and plating onto the nutrient agar using a simple streak method. The plates were incubated at $37^{\circ} \mathrm{C}$ for $24 \mathrm{~h}$ and observed for any bacterial growth.

\section{Preparation of Composite Films}

The selected essential oils eucalyptus and cinnamon were incorporated into biodegradable films using a solution casting method [7]. Composite films were prepared using 98:2 blending ratio of PLA/PBAT [8]. The various concentrations of essential oil $(1 \% \mathrm{w} / \mathrm{w}, 5 \% \mathrm{w} / \mathrm{w}$, and $10 \% \mathrm{w} / \mathrm{w}$ of polymer 
resin) were pipetted into the beaker containing $100 \mathrm{ml}$ of chloroform. Ethanol was added to the mixture to make up the equal volume in all samples. $4 \mathrm{~g}$ of polymer resin $(3.92 \mathrm{~g}$ of PLA and $0.08 \mathrm{~g}$ of PBAT) and 50\% w/w of glycerol [9] were added to each beaker and mixed using a magnetic stirrer at $23 \pm 2{ }^{\circ} \mathrm{C}$ for $24 \mathrm{~h}$. A control sample of the PLA/PBAT film was prepared using the same method, followed by the addition of only ethanol (without any essential oil).

Once the solution was solubilised, it was poured onto a glass plate $(24 \mathrm{~cm} \times 30 \mathrm{~cm})$ and spread evenly with a bent glass rod. The solution was left to dry for $24 \mathrm{~h}$ at room temperature $\left(23 \pm 2{ }^{\circ} \mathrm{C}\right)$. After $24 \mathrm{~h}$, prepared films were peeled off from the glass plates and placed into the incubator at $25{ }^{\circ} \mathrm{C}$ and $50 \%$ relative humidity (RH) for $48 \mathrm{~h}$ $[7,10]$. Eucalyptus oil-containing films was designated as PLA/PBAT-Eucalyptus ${ }^{1 \%}$, PLA/PBAT-Eucalyptus ${ }^{5 \%}$, and PLA/PBAT-Eucalyptus ${ }^{10 \%}$. Cinnamon oil containing films was named as PLA/PBAT-Cinnamon ${ }^{1 \%}$, PLA/PBAT - Cinnamon ${ }^{5 \%}$, and PLA/PBAT-Cinnamon ${ }^{10 \%}$, while control film was labelled as PLA-PBAT.

\section{Characterisation of Films}

\section{Morphological Observation}

The scanning electron microscopy (Hitachi SU70) was used to analyse the morphology of the surface and the cross-sectional area of the film sample. The sample of the film was freeze-fractured by liquid nitrogen. A small piece of sample prepared was mounted on the sample holder of SEM for observing the morphology of the surface. Analysis of the image was done with a $5-\mathrm{kV}$ accelerating voltage.

\section{Surface Colour and Optical Properties}

The surface colour of composite films was assessed using a ClearQuest XE spectrophotometer. Colour values were expressed in terms of the CIE $L$ (+ lightness, - darkness), $a$ (+ redness, - greenness), and $b$ (+ yellowness, - blueness). The spectrophotometer was standardised using a white colour plate ( $L=93.97, a=-0.88, b=1.21)$ as a background. The surface colour of films was measured by placing the film between the reflectance port and the sample clamp at three different locations. Each film was analysed three times and mean with standard deviation $L, a$ and $b$ was calculated for each sample. The colour difference between colour values of standard tile and film samples $(\Delta E)$ was calculated using the following equation:

$$
\Delta E=\left[(\Delta L)^{2}+(\Delta a)^{2}+(\Delta b)^{2}\right]^{1 / 2},
$$

where $\Delta L, \Delta a$ and $\Delta b$ are the differences between each colour value of standard colour plate and film samples, respectively [8].

UV-Vis spectrophotometer was used for measuring the optical properties using the light transmittance spectra. The films were cut into a rectangle of $3 \mathrm{~cm} \times 7 \mathrm{~cm}$ and mounted between two spectrophotometer magnetic cells. The light transmittance of the composite film was measured between the wavelengths of 200 and $700 \mathrm{~nm}$. UV-light barrier and transparency of the films were tested by determining percent transmittance at $280 \mathrm{~nm}$ (T280) and $660 \mathrm{~nm}$ (T660), respectively.

The infrared spectrum of absorption of the composite films was determined using Fourier-transform infrared spectrometer (FTIR) (Thermo Scientific, USA). The graph of the FTIR spectra in the range of $4000-400 \mathrm{~cm}^{-1}$ was obtained and analysed by converting the absorbance to the percent transmittance.

\section{Thickness and Tensile Properties}

Digital micrometre (Mitutoyo, Japan) was used to measure the thickness of the composite films. Five random locations from each film were assessed with the sensitivity of $1 \mu \mathrm{m}$. The mean values and standard deviation were calculated by measuring the thickness at three random locations [10].

Tensile properties, including tensile strength, elongation at break (EB), and elastic modulus (EM) of the composite films were measured by using the Standard ASTM D 882-88 method (ASTM D882-88, [11]) by Instron Universal Testing (Model 5565, Instron Engineering Corporation, Canton, MA, USA). In order to measure tensile properties, each film was cut into rectangular strips of $3 \times 15 \mathrm{~cm}$. Instron Instrument with a grip length of $50 \mathrm{~mm}$ and a crosshead speed of $50 \mathrm{~mm} / \mathrm{min}$ using a $500-\mathrm{N}$ load cell were used to operate until the sample broke at a certain point. The following equation was used for the calculation:

$T S=F / A$,

where $F$ is the maximum force $(N)$ required to pull apart the sample, and $A$ is the initial cross-sectional area $\left(\mathrm{m}^{2}\right)$ of the composite films.

Percentage elongation at break (EB) is the ratio between the lengths of changed and initial samples [12]. The EB was calculated using the following equation:

$E B(\%)=\left[\left(X_{f}-X_{\mathrm{o}}\right) / X_{\mathrm{o}}\right] \times 100$,

where $X_{\mathrm{o}}$ is the initial separation of the grips $(50 \mathrm{~mm})$ of samples and $X_{f}$ is the elongation of the film at the moment of failure [10,13]. Five measurements were carried out for each film, and the average values are presented. 


\section{Surface Hydrophobicity}

The surface hydrophobicity of the composite films was evaluated by determining the water contact angle (WCA) using a dynamic contact angle analyser (FTA -200 system). The films were cut into rectangular pieces $(3 \mathrm{~cm} \times 8 \mathrm{~cm})$ and placed on the stainless-steel platform fitted with a water contact angle analyser. A small drop of distilled water $(\sim 10$ $\mu \mathrm{L}$ ) was carefully applied on the surface of the film with a micro-syringe, and a water contact angle was measured by taking a picture of the water drop and determining its ability to spread on the surface of the film. Drop shape was evaluated in terms of the contact angle between the substrate surface and a tangent from the edge to the contour of the drop. The mean and standard deviation for each sample were calculated by taking triplicate measurements.

\section{Antibacterial Activity}

The antibacterial activity and efficacy of the blend films, containing eucalyptus and cinnamon essential oils, were determined against Escherichia coli (NCTC 9001) and Staphylococcus aureus (ATCC 25923) using the Japanese Industrial Standard (JIS Z 2801:2000) [14]. In brief, composite films were cut into four square pieces of $5 \mathrm{~cm} \times 5 \mathrm{~cm}$ and sterilised by UV for $20 \mathrm{~min}$ both sides. Films were then placed on the aluminium plate $(5.5 \mathrm{~cm} \times 5.5 \mathrm{~cm})$ and transferred into a sterilised petri dish containing filter paper which was wetted with autoclaved water. The test inoculum was prepared aseptically to form an initial bacterial population of $1 \times 10^{6} \mathrm{CFU} / \mathrm{ml}$ and pipetted $400 \mu \mathrm{l}$ on each film. Each petri dish containing the sample was incubated at $37{ }^{\circ} \mathrm{C}$, relative humidity (RH) of $>90 \%$ for $24 \mathrm{~h}$. One set of inoculated samples was immediately tested after $0 \mathrm{~h}$ by placing the samples in a sterilised stomacher bag. $20 \mathrm{ml}$ of minimum recovery diluent (MRD) was added to each stomacher bag and then mixed gently into the stomacher (AGB Scientific-Lab blender 400) for 40-45 s. The absorbance was measured at a wavelength of $600 \mathrm{~nm}$. The viable cell count of bacteria was determined by the agar plate culture method.

\section{Biofilm Inhibition}

Pathogenic bacteria E. coli was employed in order to determine the biofilm inhibition $[15,16]$ of composite films incorporated with essential oils. Composite films were cut into three square pieces of $4 \mathrm{~cm} \times 4 \mathrm{~cm}$ (one set of positive control and two sets for biofilm inhibition) and sterilised by UV light for $20 \mathrm{~min}$ both sides. The bacterial culture $\left(1 \times 10^{6} \mathrm{CFU} / \mathrm{ml}\right) 100 \mu \mathrm{l}$ was kept on the film and incubated at $37{ }^{\circ} \mathrm{C}$, relative humidity (RH) of $>90 \%$ for $72 \mathrm{~h}$. After the incubation, E. coli biofilms were tested by staining them with crystal violet.

Each film was rinsed trice with sterile water and then stained by $1 \% \mathrm{w} / \mathrm{v}$ crystal violet ( $500 \mu \mathrm{l})$ for $45 \mathrm{~min}$. After staining them, test samples were washed thrice with sterile distilled water. Biofilms were quantified by eluting crystal violet with $95 \%$ ethanol $(500 \mu \mathrm{l})$ for $10 \mathrm{~min}$ and transferring aliquots $(100 \mu \mathrm{l})$ to 96 -well plate. The absorbance values were taken at a wavelength of $600 \mathrm{~nm}$, and the inhibition of E. coli biofilm was measured.

\section{Statistical Analysis}

All measurements were carried out in triplicate. Analysis of variance (ANOVA) was used to calculate the statistical difference and Fischer's least significant difference test for multiple comparisons using STATGRAPHICS Centurion XV software (Stat Point Technologies Inc. Warrenton, VA, USA). Differences were considered to be significant if the value of $p<0.05$. All results are expressed as mean \pm standard deviation.

\section{Results and Discussion}

\section{Minimum Inhibitory Concentration and Minimum Bactericidal Concentration}

The MIC and MBC analyses were carried out by using the microtiter broth dilution assay. As seen in Fig. 1, some of the tested essential oils showed strong antimicrobial activity against both $S$. aureus (Gram positive) and E. coli (Gram negative) bacteria. The MIC results showed that essential oils such as eucalyptus, thyme, cinnamon and rosemary have the highest potential in inhibiting the visible growth of $E$. coli with $95-100 \%$, whereas eucalyptus, thyme, cinnamon and fenugreek essential oils showed 80-100\% inhibition against $S$. aureus. Black pepper, turmeric, lavender, lemon and neem were observed to possess low antibacterial activity against both bacteria as compared to eucalyptus, thyme, cinnamon and fenugreek essential oils at $3.125 \%$ concentration. Cinnamon and eucalyptus oils were the most effective essential oils inhibiting $85-100 \%$ bacterial growth of $S$. aureus and E. coli. Of all the essential oils, lemon showed the lowest antibacterial activity, with $4 \%$ inhibition of E. coli and no inhibition of $S$. aureus.

MBC result indicated that eucalyptus and clove essential oils showed bactericidal activity against $E$. coli and $S$. aureus, while thyme showed bactericidal only against $S$. aureus. Jurado et al. [17] discussed the antimicrobial activity of essential oils and indicated that the cinnamon oil and eucalyptus oil having high antimicrobial activity against a 
wide range of bacteria [17]. However, the various concentrations of rosemary, fenugreek, black pepper, turmeric, lavender, lemon and neem essential oils showed no bactericidal activity against $E$. coli and $S$. aureus at the tested concentration. MIC and MBC results show that eucalyptus and cinnamon essential oils were the most effective against both tested bacteria S. aureus and E. coli.

\section{Characterisation of Blend Films}

\section{Surface Colour}

The surface colour of the biodegradable films for active food packaging plays an essential role in the appearance and consumer acceptability. Films were observed to be smooth without any ruptures, flexible and less transparent depending on the type of essential oil and its concentration being used. As shown in Tables 1 and 2 , the $L, a$ and $b$ values of the composite films increased significantly $(p<0.05)$ after the incorporation of higher concentration of essential oil. The increase in concentration caused the film surface to become darker.

In addition, the greenness and yellowish in PLA/PBATEucalyptus ${ }^{10 \%}$ film increased significantly by 1.08 times each, whereas in PLA/PBAT-Cinnamon ${ }^{10 \%}$ film increased by 1.74 and 2.9 times, respectively. The total colour difference ( $\Delta E$ values) of PLA/PBAT blend film increased significantly after the incorporation of cinnamon essential oils. In contrast, in the presence of the eucalyptus oils, $\Delta E$ values decrease significantly $(p<0.05)$. The $\Delta E$ values for

Fig. 1 Percentage inhibition of essential oils at the minimum concentration (3.125\%) against E. coli and S. aureus

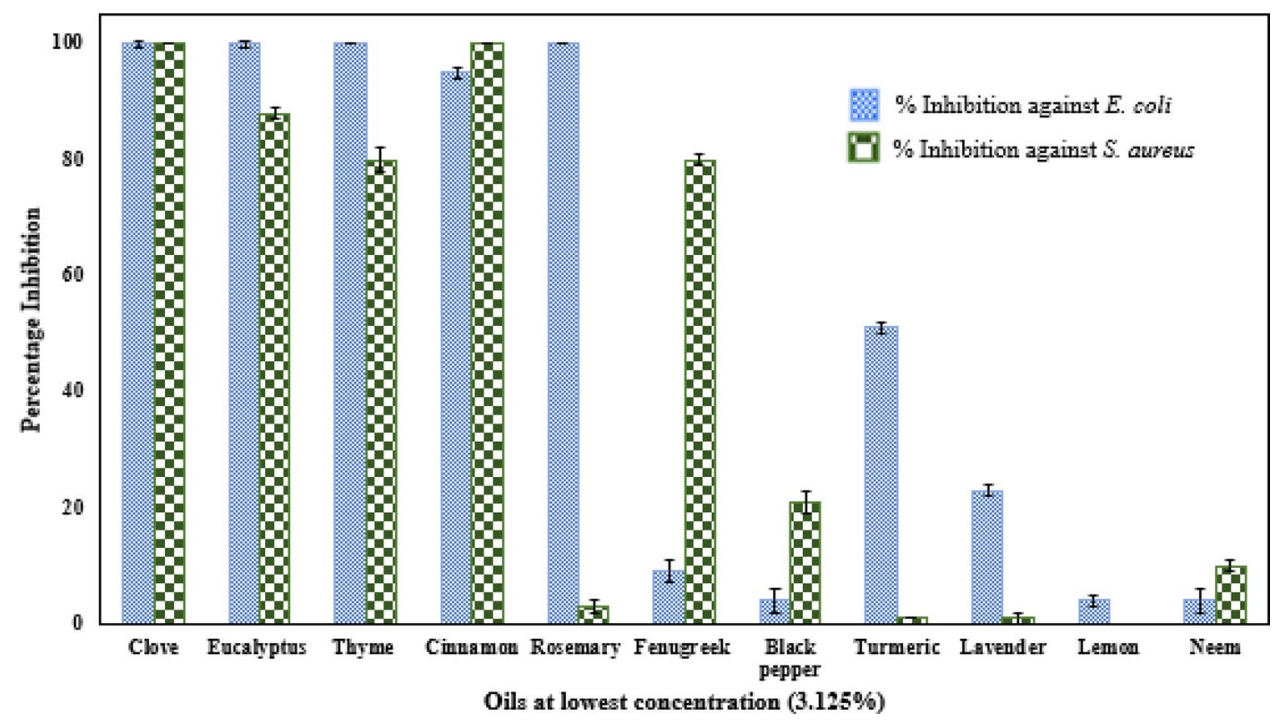

Table 1 Surface colour, UV barrier and transparency of composite films incorporated with Eucalyptus oil

\begin{tabular}{lllllll}
\hline Film & $L$ & $a$ & $b$ & $\Delta E$ & $T_{(280)}$ & $T_{(600)}$ \\
\hline PLA/PBAT & $91.56 \pm 0.57^{\mathrm{a}}$ & $-1.08 \pm 0.06^{\mathrm{a}}$ & $1.34 \pm 0.03^{\mathrm{b}}$ & $2.42 \pm 0.02^{\mathrm{c}}$ & $0.05 \pm 0.02^{\mathrm{a}}$ & $72.46 \pm 0.05^{\mathrm{d}}$ \\
PLA/PBAT-Eucalyptus $^{1 \%}$ & $90.58 \pm 0.36^{\mathrm{a}}$ & $-1.08 \pm 0.03^{\mathrm{a}}$ & $1.25 \pm 0.02^{\mathrm{a}}$ & $3.39 \pm 0.03^{\mathrm{d}}$ & $0.04 \pm 0.01^{\mathrm{a}}$ & $71.37 \pm 0.04^{\mathrm{c}}$ \\
PLA/PBAT-Eucalyptus $^{5 \%}$ & $92.79 \pm 0.97^{\mathrm{a}}$ & $-1.15 \pm 0.03^{\mathrm{a}, \mathrm{b}}$ & $1.26 \pm 0.03^{\mathrm{a}}$ & $1.24 \pm 0.03^{\mathrm{b}}$ & $0.03 \pm 0.00^{\mathrm{a}}$ & $69.36 \pm 0.10^{\mathrm{b}}$ \\
PLA/PBAT-Eucalyptus $^{10 \%}$ & $93.07 \pm 0.88^{\mathrm{a}}$ & $-1.17 \pm 0.02^{\mathrm{b}}$ & $1.45 \pm 0.04^{\mathrm{c}}$ & $0.99 \pm 0.03^{\mathrm{a}}$ & $0.03 \pm 0.01^{\mathrm{a}}$ & $67.68 \pm 0.05^{\mathrm{b}}$ \\
\hline
\end{tabular}

${ }^{*}$ The letters $(\mathrm{a}-\mathrm{d})$ at each concentration indicate groups that are significantly different $(p<0.05)$

Table 2 Surface colour, UV barrier and transparency of composite films incorporated with Cinnamon oil

\begin{tabular}{lllllll}
\hline Film & $L$ & $a$ & $b$ & $\Delta E$ & $T_{(280)}$ & $T_{(600)}$ \\
\hline PLA/ PBAT & $91.56 \pm 0.57^{\mathrm{a}}$ & $-1.08 \pm 0.06^{\mathrm{a}}$ & $1.34 \pm 0.03^{\mathrm{a}}$ & $2.42 \pm 0.02^{\mathrm{a}}$ & $0.05 \pm 0.00^{\mathrm{b}}$ & $72.46 \pm 0.45^{\mathrm{a}}$ \\
PLA/PBAT-Cinnamon $^{1 \%}$ & $91.38 \pm 1.19^{\mathrm{a}}$ & $-1.30 \pm 0.02^{\mathrm{b}}$ & $1.81 \pm 0.03^{\mathrm{b}}$ & $2.69 \pm 0.04^{\mathrm{b}}$ & $0.01 \pm 0.01^{\mathrm{a}}$ & $79.74 \pm 0.74^{\mathrm{d}}$ \\
PLA/PBAT-Cinnamon $^{5 \%}$ & $90.63 \pm 0.48^{\mathrm{a}}$ & $-1.39 \pm 0.03^{\mathrm{c}}$ & $2.44 \pm 0.03^{\mathrm{c}}$ & $3.60 \pm 0.07^{\mathrm{c}}$ & $0.01 \pm 0.00^{\mathrm{a}}$ & $77.86 \pm 0.27^{\mathrm{c}}$ \\
PLA/PBAT-Cinnamon $^{10 \%}$ & $90.31 \pm 0.79^{\mathrm{a}}$ & $-1.88 \pm 0.02^{\mathrm{d}}$ & $3.88 \pm 0.02^{\mathrm{d}}$ & $4.66 \pm 0.10^{\mathrm{d}}$ & $0.01 \pm 0.00^{\mathrm{a}}$ & $77.27 \pm 0.36^{\mathrm{b}}$ \\
\hline
\end{tabular}

${ }^{*}$ The letters $(\mathrm{a}-\mathrm{d})$ at each concentration indicate groups that are significantly different $(p<0.05)$ 
both essential oils were significantly different from each other. The yellowish and more opaque appearance in PLA/ PBAT-cinnamon oil films could be due to the phenolic compounds found in cinnamon essential oils. Similar results were observed in many studies such as, Liu et al. [18] had incorporated oregano essential oil in the packaging film and found a pale-yellow film [18]. Moreover, Vahedikia et al. [19] had also observed similar results on the incorporation of cinnamon oil in the active zein films [19].

\section{Morphology of the Surface}

The thickness of the composite films was measured using a digital micrometre. The results indicated that as the concentration of the eucalyptus oil in the PLA/PBAT blend films increases from 1 to $10 \%$, the thickness of the films increased significantly $(p>0.05)$ by $20-35 \%$ (Table 3$)$. A similar trend was observed for the cinnamon oil incorporated PLA/PBAT blend film (Table 4). It was also found that the PLA/PBATcinnamon oil films were thicker than PLA/PBAT- eucalyptus oil films.

However, Pola et al. [20] observed no significant difference in the thickness of the cellulose film with the addition of oregano oil at different concentrations [20]. The variation in the results could be expected because a higher concentration of selected essential oils was used in the preparation of composite films that caused the uneven dispersion and the incorporation of the essential oil droplets into the film matrix.

\section{Optical Properties}

Optical properties such as UV-light barrier and transparency of the composite films play a significant role in the food product appearance and consumer acceptability. The
UV blocking properties of the film is very beneficial in terms of preventing packaged foods from phytochemical reactions that are caused by UV light. In order to determine the optical properties of composite films, the light transmittance spectra were measured at the wavelength of 280-700 nm (Fig. 2a and b). The transmittance of control PLA/PBAT film at the wavelength of $300 \mathrm{~nm}$ was higher compared to films incorporated with essential oils, which exhibited a low transmittance at this wavelength.

As shown in Fig. 2a, the transmittance of composite films with eucalyptus essential oil increased significantly above the wavelength of $280 \mathrm{~nm}$. In contrast, transmittance of films containing cinnamon oil increased only above $380 \mathrm{~nm}$. Also, the results presented in Tables 1 and 2 indicate that biodegradable films incorporated with essential oils have a higher UV-light barrier compared to the control PLA/PBAT film. PLA/PBAT-eucalyptus oil films (10\%) have exhibited $40 \%$ increase of UV-blocking property than control film while PLA/PBAT-cinnamon oil films (10\% w/w) exhibited $80 \%$ increase of UV-blocking property. The best UV-blocking properties were observed in PLA/ PBAT - cinnamon oil films due to a high concentration of phenolic compound eugenol, which can absorb UV light.

In addition, the transparency at $\mathrm{T}_{600}\left(\mathrm{~T}_{600}\right.$ for visible light) of PLA/PBAT films significantly increased by 1.10 fold with the incorporation of cinnamon essential oil. In contrast, transparency of PLA/PBAT-eucalyptus significantly decreased by 0.93 -fold as compared to the control PLA/PBAT blend film. (Tables 1 and 2). The transparency of the films decreases as the concentration of eucalyptus oils increases from 1 to $10 \%$ (Table 1) due to the presence of eugenol which gives a pale-yellow colour to films. Thus PLA/PBAT — cinnamon oil films are more likely to be used as a packaging material due to their high UV blocking properties.
Table 3 Thickness, tensile properties and hydrophobicity of the composite films with Eucalyptus oil

\begin{tabular}{lllll}
\hline Film & Thickness $(\mu \mathrm{m})$ & TS $(\mathrm{MPa})$ & EB $(\%)$ & WCA \\
\hline PLA/PBAT & $36.71 \pm 1.04^{\mathrm{b}}$ & $1.35 \pm 0.03^{\mathrm{c}}$ & $5.63 \pm 0.17^{\mathrm{a}}$ & $61.61 \pm 8.05^{\mathrm{a}}$ \\
PLA/PBAT-Eucalyptus $^{1 \%}$ & $23.32 \pm 0.95^{\mathrm{a}}$ & $1.68 \pm 0.02^{\mathrm{d}}$ & $31.41 \pm 0.45^{\mathrm{b}}$ & $64.63 \pm 2.41^{\mathrm{a}}$ \\
PLA/PBAT-Eucalyptus $^{5 \%}$ & $56.76 \pm 0.35^{\mathrm{c}}$ & $1.13 \pm 0.00^{\mathrm{b}}$ & $30.19 \pm 2.04^{\mathrm{b}}$ & $73.24 \pm 5.53^{\mathrm{b}}$ \\
PLA/PBAT-Eucalyptus $^{10 \%}$ & $83.32 \pm 1.27^{\mathrm{d}}$ & $0.97 \pm 0.02^{\mathrm{a}}$ & $29.23 \pm 1.04^{\mathrm{b}}$ & $78.32 \pm 1.74^{\mathrm{b}}$ \\
\hline
\end{tabular}

${ }^{*}$ The letters $(\mathrm{a}-\mathrm{d})$ at each concentration indicate groups that are significantly different $(p<0.05)$
Table 4 Thickness, tensile properties and hydrophobicity of the composite films with Cinnamon oil

\begin{tabular}{lllll}
\hline Film & Thickness $(\mu \mathrm{m})$ & TS $(\mathrm{MPa})$ & EB $(\%)$ & WCA \\
\hline PLA/ PBAT & $36.71 \pm 1.04^{\mathrm{a}}$ & $1.35 \pm 0.03^{\mathrm{d}}$ & $5.63 \pm 0.17^{\mathrm{a}}$ & $61.61 \pm 8.05^{\mathrm{a}}$ \\
PLA/PBAT-Cinnamon $^{1 \%}$ & $63.33 \pm 0.86^{\mathrm{b}}$ & $0.92 \pm 0.00^{\mathrm{c}}$ & $29.18 \pm 0.81^{\mathrm{b}}$ & $63.88 \pm 3.61^{\mathrm{a}}$ \\
PLA/PBAT-Cinnamon $^{5 \%}$ & $73.33 \pm 1.78^{\mathrm{c}}$ & $0.84 \pm 0.01^{\mathrm{b}}$ & $29.12 \pm 1.06^{\mathrm{b}}$ & $70.18 \pm 2.69^{\mathrm{a}}$ \\
PLA/PBAT-Cinnamon $^{10 \%}$ & $130.00 \pm 2.08^{\mathrm{d}}$ & $0.78 \pm 0.00^{\mathrm{a}}$ & $28.50 \pm 0.99^{\mathrm{b}}$ & $84.61 \pm 8.89^{\mathrm{b}}$ \\
\hline
\end{tabular}

${ }^{*}$ The letters $(a-d)$ at each concentration indicate groups that are significantly different $(p<0.05)$ 

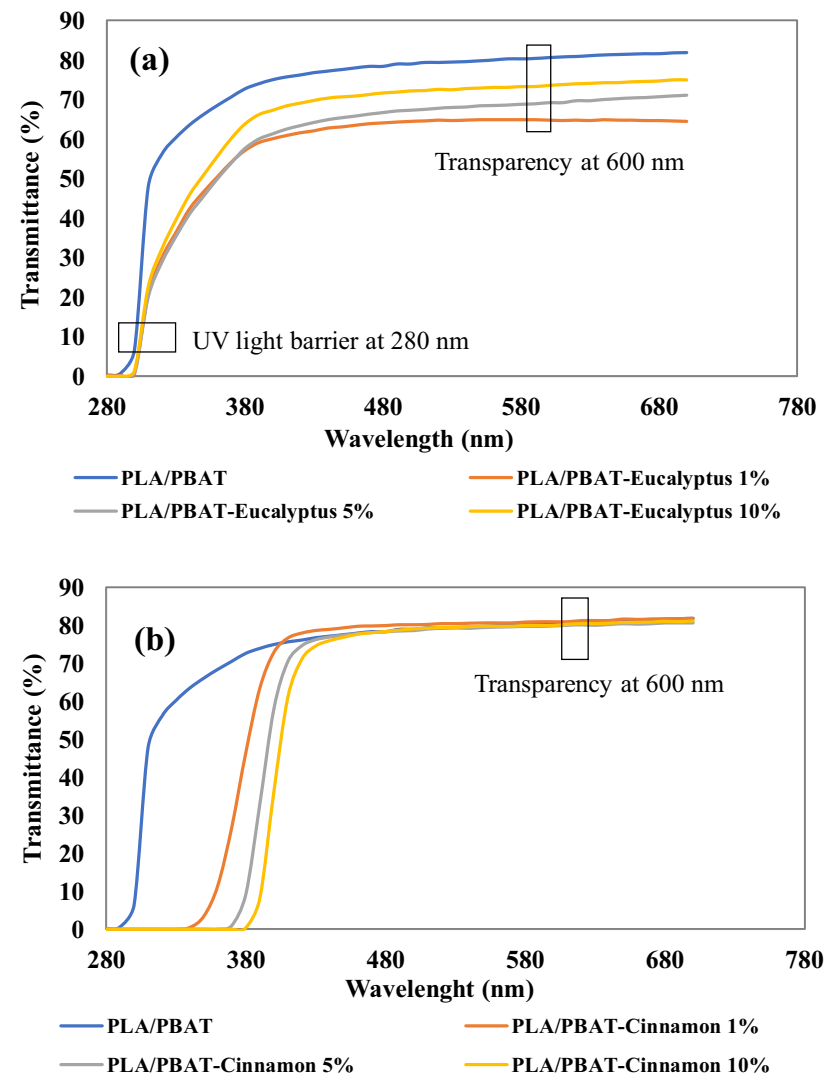

Fig. 2 Light transmittance spectra of PLA/PBAT incorporated with a Eucalyptus oil and $\mathbf{b}$ Cinnamon oil composite film

Various studies on essential oil incorporated packaging films demonstrated that the UV barrier property had increased and transparency of the packaging film decreased with the incorporation of essential oil such as clove essential oil [21, 22], cinnamon oil [23], rosemary oil [24] and oregano oil [25].

\section{FTIR Analysis}

Fourier transform infrared spectroscopy (FTIR) is a qualitative analysis used to evaluate the chemical properties of the samples. The FTIR spectra curves have been divided into four regions depending on the wavelength. Wavelength below $800 \mathrm{~cm}^{1}$ was designated as the first region, wavelength between 800 and $1500 \mathrm{~cm}^{-1}$ was designated the second region, the third region was between 1500 and $3000 \mathrm{~cm}^{-1}$, and the fourth region ranged above $3000 \mathrm{~cm}^{-1}$. The overlapping peaks in the first, second and third regions at 727,884 and $1445 \mathrm{~cm}^{-1}$, respectively, were determined as the vibrations of aromatic compounds with $\mathrm{C}-\mathrm{H}$ and $\mathrm{C}-\mathrm{C}$ stretch (in the ring). The second region also proved to possess the presence of functional groups such as aliphatic amines, alcohols, carboxylic acids, esters, ethers and alkanes. Aliphatic amines showed up peaks in all samples in the range of $1073-1079 \mathrm{~cm}^{-1}$ with $\mathrm{C}-\mathrm{N}$ stretch. The $\mathrm{C}-\mathrm{O}$ vibrational stretching showed the presence of alcohols, carboxylic acids, esters and ethers that were in the range of $1176-1180 \mathrm{~cm}^{-1}$. The existence of alkanes in the composite films was determined by their $\mathrm{C}-\mathrm{H}$ vibrational stretching in the range of $1353-1364 \mathrm{~cm}^{-1}$. In the third area, esters, aldehydes and alkanes were identified. Esters showed up a strong peak in the range of $1740-1745 \mathrm{~cm}^{-1}$ with $\mathrm{C}=\mathrm{O}$ vibrational stretching, whereas aldehydes and alkanes ranged from 2846 to $2849 \mathrm{~cm}^{-1}$ and 2904 to $2918 \mathrm{~cm}^{-1}$, respectively. Last, in the fourth region, the occurrence of $\mathrm{O}-\mathrm{H}$ stretching resulted in a wide peak at $3265-3316 \mathrm{~cm}^{-1}$ wavelength range indicating the presence of alcohols and phenols.

The peaks showing the occurrence of alcohol functional groups became shorter and weaker as the concentration of the essential oil increased in the composite films. It was due to the lesser amounts of ethanol used to prepare different composite films with increasing concentration of a specific essential oil. In addition, peaks indicating the presence of functional groups shifted to shorter peaks as the concentration of essential oils increased, which could be due to that the components of essential oils are susceptible to chemical transformation, oxidation and polymerization [26].

The FTIR results showed that all samples displayed similar transmittance peaks within the same wavelength regions, indicating that PLA/PBAT composite films have similar functional groups. It was also determined that the incorporation of essential oils to PLA/PBAT blend films did not change its chemical composition because there were no chemical reactions.

\section{Tensile Properties of the Films}

The mechanical properties including tensile strength and elongation at break (EB) of composite films were examined through tensile tests using the Universal Testing Machine (Zwick/Roell-A730271, USA). The effect of oil incorporation in biodegradable films onto their tensile properties was determined and the results are presented in Table 2. The tensile strength of control film was $1.35 \mathrm{MPa}$ and decreased significantly $(p<0.05)$ after incorporation of essential oils with the exception in PLA/PBAT-Eucalyptus $^{1 \%}$ and PLA/PBAT-Cinnamon ${ }^{1 \%}$ films which had tensile strength values of $1.68 \mathrm{MPa}$ and $0.92 \mathrm{MPa}$, respectively. It was also observed that the tensile strength of the eucalyptus oil composite film decreased significantly by $17 \%$, while for cinnamon oil composite film tensile strength decreased by $42 \%$ as the concentration of the essential oil in the composite film increased. The continuously increasing concentration of oil can cause an increase in pore size of the film matrix that leads to weakened structure and increased number of rupture points. These results are similar to the findings obtained by Moradi et al. [27]. They had 
developed edible film incorporated with Zataria multiflora Boiss essential oil and grape seed oils and films exhibited lower tensile strength [27].

The elongation at break (EB) of the composite films increased significantly $(p<0.05)$ with the incorporation of essential oils indicating their flexibility. The elongation at break of PLA/PBAT — eucalyptus oil and PLA/PBAT — cinnamon oil increased by 5.2 times and 5.1 times, respectively, as compared with the control film. The improved flexibility of the composite films is due to a better interaction between PLA/PBAT polymer matrix and essential oil.

Concerning the PLA/PBAT composite films added with eucalyptus and cinnamon essential oils at various concentrations $(1 \%, 5 \%$ and $10 \% \mathrm{w} / \mathrm{w})$, the tensile strength decreased with the increasing oil concentration. Thus, the addition of essential oil has a significant impact on the tensile properties of biodegradable films and is dependent on the interactions between polymer matrix and certain oil components [28]. A study carried out by Hosseini et al. [25] also found the decrease in the tensile strength and increase in the EB with the incorporation of the oregano essential oil in the packaging film [25].

\section{Water Contact Angle (WCA)}

Surface hydrophobicity is very important in terms of active food packaging, especially biodegradable films that can be sensitive to water or moisture and is assessed by measuring the water contact angle (WCA) of the films [29]. Usually, high contact angle indicates a strong surface hydrophobicity. All 5\% and 10\% films incorporated with different essential oils can be considered as biodegradable films with the hydrophobic surface because the WCA of these films is higher than $65^{\circ}$ [30]. It was also observed that the surface hydrophobicity of the eucalyptus oil composite film increased significantly by 1.27 times with respect to the control film, whereas in the cinnamon oil composite film it increased by 1.38 times as the concentration of the essential oil increases. Similar results were observed in various studies such as Atef et al. [31], who had incorporated savory essential oil in agar cellulose film and observed a significant increase in the WCA [31]. In addition, Ojagh et al. [32] found the increase in film hydrophobicity by the incorporation of cinnamon essential oil in chitosan-based films [32]. Therefore, the concentration of essential oils in biodegradable films plays a vital role in reducing the wettability of active packaging and improving quality and safety of wrapped food products. Based on the surface hydrophobicity, composite films may be arranged as follows in decreasing order: PLA/PBATcinnamon oil > PLA/PBAT—eucalyptus oil.

\section{Antibacterial Activity}

The antimicrobial activity and efficacy of the eucalyptus oil composite films and cinnamon oil composite film against $E$. coli (NCTC 9001) and S. aureus (ATCC 25923) are shown in Fig. 3a-d. The control PLA/PBAT film showed $9.0 \mathrm{log}$ $\mathrm{CFU} / \mathrm{ml}$ growth of $E$. coli and $8.47 \log \mathrm{CFU} / \mathrm{ml}$ growth of $S$. aureus after $24 \mathrm{~h}$ incubation. Figure $3 \mathrm{a}$, b shows the reduction of $E$. coli growth by $3.34 \log \mathrm{CFU} / \mathrm{ml}$ and $S$. aureus by $2.61 \log \mathrm{CFU} / \mathrm{ml}$ in the presence of eucalyptus oil composite film (5 wt\%). In addition, the eucalyptus oil composite film (10 wt $\%$ ) led to the reduction of $S$. aureus growth by 3.04 $\log \mathrm{CFU} / \mathrm{ml}$ and $E$. coli by $3.58 \log \mathrm{CFU} / \mathrm{ml}$ of the $E$. coli with respect to the control. Figure $3 \mathrm{c}$, d shows that, in the presence of cinnamon oil composite film 1\%, 5\%,10\% the growth of S. aureus reduced by $2.57,3.44$ and $4.26 \log$ CFU/ $\mathrm{ml}$, respectively. However, $5 \%$ and $10 \%$ of the cinnamon oil composite film reduces the $E$. coli growth by 3.80 and 3.94 $\log \mathrm{CFU} / \mathrm{ml}$, respectively.

The results indicate that antimicrobial activity is highly depended on the type of the essential oil, on its concentration and type of bacteria being used. It was also observed that cinnamon oil incorporated films exhibited higher antimicrobial activity against $S$. aureus than the eucalyptus oil composite films. Cinnamon oil was also more effective against gram-negative $E$. coli compared to the eucalyptus essential oils. The effectiveness of essential oil against both bacteria might be associated with cell permeability and composition of essential oil. It could be because of incubation temperature $\left(37^{\circ} \mathrm{C}\right)$ increases cell permeability allowing essential oil to dissolve faster and cause damage to the membrane, which results in cell death. In fact, essential oil contains a high concentration of eugenol, which disrupts the cytoplasmic membrane [33].

\section{Biofilm Inhibition}

Biofilm formation is a complex structured aggregation of microorganisms that can cause some severe problems in the food industry due to persistent bacteria. Removal of biofilms requires costly efforts that can lead to environmental issues and lost productivity. Figure 4 shows that composite films containing eucalyptus and cinnamon essential oils proved to be effective in inhibiting the biofilm formation by E. coli, and their activity is directly proportional to the concentration of oil.

The eucalyptus oil composite film had shown biofilm inhibition from 57.49 to $84.37 \%$ and cinnamon oil exhibited biofilm between 61.16 and $89.82 \%$, as the concentration of oils in the composite film increases from 1 to $10 \%$. Therefore, the PLA/PBAT blend films incorporated with cinnamon essential oils showed higher biofilm inhibition properties compared to eucalyptus oil composite film. The results 
(a)

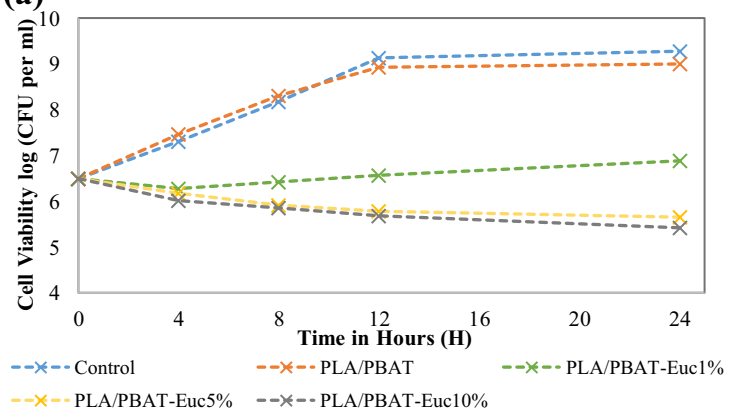

(c)

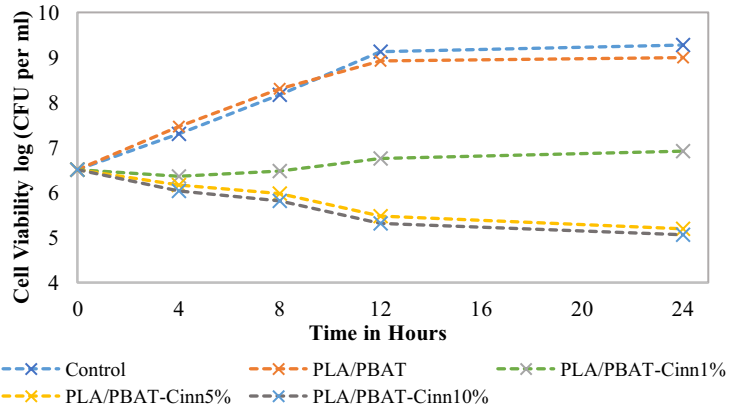

(b)

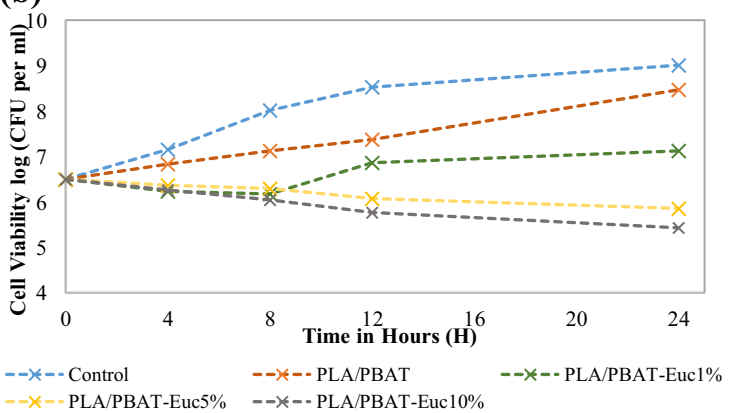

(d)

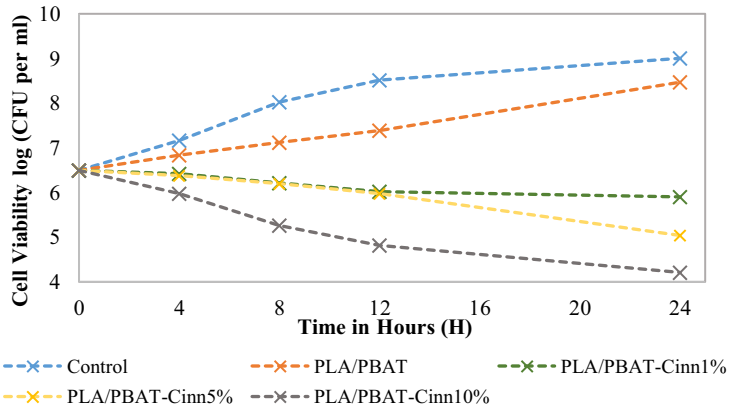

Fig. 3 Antimicrobial efficiency of composite film. a Effect of Eucalyptus oil composite film on E. coli, b effect of Cinnamon oil composite film on $S$. aureus (2c) effect of Eucalyptus oil composite film on E. coli and (2d) effect of Cinnamon oil composite film on $S$. aureus

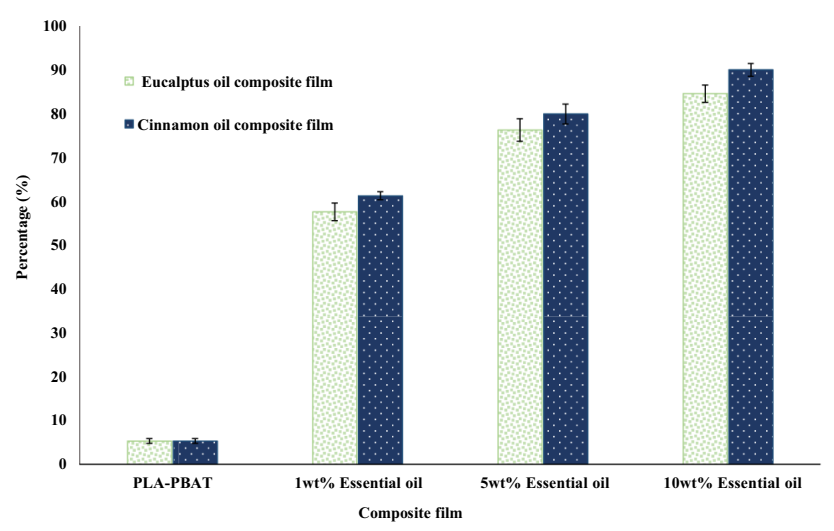

Fig. 4 Biofilm inhibition of PLA/PBAT-Eucalyptus oil composite film and PLA/PBATCinnamon oil composite film against $E$. coli

also indicated that high concentration (10\%) of essential oil inhibits biofilm formation on all tested composite films.

The inhibitory action of these essential oils against biofilm is due to the presence of eugenol derivatives such as isoeugenol, 2 methoxy-4-propylphenol and 4-ethylguaiacol which can inhibit biofilm formation [34]. Moreover, cinnamon oil was more effective than eucalyptus oils because they contain higher concentrations of eugenol $3.52 \mathrm{mg} \mathrm{g}^{-1}$ [35]. In comparison with previous studies, the cinnamon oil composite film had shown more effective results than Zataria multiflora Boiss essential oil [36] and oregano essential oil
[37] incorporated in different polymer-based packaging. In addition, with respect to the polymer (PLA/PBAT) based packaging film, cinnamon oil PLA/PBAT composite film had exhibited better antimicrobial activity than other natural compounds like ferulic acid [10] and grape seed extract [7, 13].

\section{Conclusions}

Cinnamon and eucalyptus oil had shown highest antibacterial property among all tested essential oils. The incorporation of eucalyptus and cinnamon oils with different concentrations $(1 \%, 5 \%$ and $10 \%)$ into the PLA/PBAT blend films greatly influenced the film properties such as optical, mechanical, surface hydrophobicity, antimicrobial activity and biofilm inhibition. PLA/PBAT_cinnamon oil films (10\%) exhibited $80 \%$ increase of UV-blocking property, whereas PLA/PBAT-eucalyptus oil films (10\%) exhibited $40 \%$ increase. Moreover, the transparency of PLA/PBATfilms increased by 1.10 -fold with the incorporation of cinnamon essential oil, and decreased by 0.93 -fold with the addition of eucalyptus oil. The decrement in tensile strength and increment in the flexibility was observed with the increase in the concentration of essential oils. The tensile strength of the eucalyptus oil composite film decreased by $17 \%$, while cinnamon oil composite film decreased by $42 \%$, as 
the concentration of the essential oils increased. Cinnamon oil incorporated films exhibited higher antimicrobial activity against E.coli and $S$. aureus compared to the eucalyptus oil composite films. The composite film having $10 \%$ eucalyptus oil inhibits biofilm by $84.37 \%$, while cinnamon oil $(10 \%)$ composite film exhibited biofilm inhibition by $89.82 \%$. The cinnamon oil composite biodegradable films with strong antimicrobial activity, biofilm inhibition and UV blocking properties can be used as an active packaging to improve the quality and increase the shelf-life of foods by preventing the growth of foodborne pathogens and photochemical reactions caused by UV light.

Aknowledgements Authors would like to acknowledge the funding from Technological University Dublin-City Campus (formally Dublin Institute of Technology) under the Fiosraigh Scholarship programme, 2017.

\section{Compliance with Ethical Standards}

Conflict of interest The authors declare no conflict of interest.

\section{References}

1. Kumar KVP, Suneetha J, Kumari BA (2018) Active packaging systems in food packaging for enhanced shelf life. Int J Pharmacogn Phytochem 7(6):2044-2046

2. Vilela C, Kurek M, Hayouka Z, Röcker B, Yildirim S, Antunes MDC, Freire CS (2018) A concise guide to active agents for active food packaging. Trends Food Sci Tech 80:212-222

3. Geueke B, Groh K, Muncke J (2018) Food packaging in the circular economy: overview of chemical safety aspects for commonly used materials. J Clean Prod 193:491-505

4. Bouyahya A, Lagrouh F, El Omari N, Bourais I, El Jemli M, Marmouzi I, Dakka N (2020) Essential oils of Mentha viridis rich phenolic compounds show important antioxidant, antidiabetic, dermatoprotective, antidermatophyte and antibacterial properties. Biocatal Agric Biotechnol 23:101471

5. Jaiswal AK, Gupta S, Abu-Ghannam N, Cox S (2011) Application of Baranyi function to model the antibacterial properties of solvent extract from Irish York cabbage against food spoilage and pathogenic bacteria. Food Sci Technol Int 17(5):495-502

6. Knaack D, Idelevich EA, Schleimer N, Molinaro S, Kriegeskorte A, Peters G, Becker K (2019) Bactericidal activity of bacteriophage endolysin HY-133 against Staphylococcus aureus in comparison to other antibiotics as determined by minimum bactericidal concentrations and time-kill analysis. Diagn Micr Infec Dis 93(4):362-368

7. Shankar S, Rhim JW (2018) Preparation of antibacterial poly (lactide)/poly (butylene adipate-co-terephthalate) composite films incorporated with grapefruit seed extract. Int J Biol Macro 120:846-852

8. Wang LF, Rhim JW, Hong SI (2016) Preparation of poly (lactide)/poly (butylene adipate-co-terephthalate) blend films using a solvent casting method and their food packaging application. Lwt-Food Sci Technol 68:454-461

9. Sharma S, Barkauskaite S, Duffy B, Jaiswal S, Jaiswal AK (2020) Characterisation and antimicrobial activity of biodegradable active packaging enriched with clove and thyme essential oil for food packaging application. Foods MDPI 9:1117. https://doi. org/10.3390/foods9081117

10. Sharma S, Jaiswal AK, Duffy B, Jaiswal S (2020) Ferulic acid incorporated active films based on poly (lactide)/poly (butylene adipate-co-terephthalate) blend for food packaging. Food Packag Shelf Life 24:100491

11. Standard, A.S.T.M. D. (2002) Standard test method for tensile properties of thin plastic sheeting. Annual book of ASTM standards. D882-88

12. Petroudy SD (2017) Physical and mechanical properties of natural fibers advanced high strength natural fibre composites in construction. Elsevier, Amsterdam, pp 59-83

13. Shankar S, Rhim JW (2018) Antimicrobial wrapping paper coated with a ternary blend of carbohydrates (alginate, carboxymethyl cellulose, carrageenan) and grapefruit seed extract. Carbohydr Polym 196:92-101

14. Jis Z (2000) 2801: 2000 Antimicrobial Products-Test for Antimicrobial Activity and Efficacy. Japanese Standards Association, Tokyo, Japan

15. Erriu M, Genta G, Tuveri E, Orrù G, Barbato G, Levi R (2012) Microtiter spectrophotometric biofilm production assay analyzed with metrological methods and uncertainty evaluation. Measurement 45(5): 1083-1088

16. Jaiswal S, Bhattacharya K, McHale P, Duffy B (2015) Dual effects of $\beta$-cyclodextrin-stabilised silver nanoparticles: enhanced biofilm inhibition and reduced cytotoxicity. J Mater Sci Mater Med 26(1):52

17. Reyes-Jurado F, Franco-Vega A, Ramírez-Corona N, Palou E, López-Malo A (2015) Essential oils: antimicrobial activities, extraction methods, and their modeling. Food Eng Rev 7(3):275-297

18. Liu D, Li H, Jiang L, Chuan Y, Yuan M, Chen H (2016) Characterization of active packaging films made from poly (lactic acid)/ poly (trimethylene carbonate) incorporated with oregano essential oil. Molecules 21(6):695

19. Vahedikia N, Garavand F, Tajeddin B, Cacciotti I, Jafari SM, Omidi T, Zahedi Z (2019) Biodegradable zein film composites reinforced with chitosan nanoparticles and cinnamon essential oil: physical, mechanical, structural and antimicrobial attributes. Colloid Surface B 177:25-32

20. Pola CC, Medeiros EA, Pereira OL, Souza VG, Otoni CG, Camilloto GP, Soares NF (2016) Cellulose acetate active films incorporated with oregano (Origanum vulgare) essential oil and organophilic montmorillonite clay control the growth of phytopathogenic fungi. Food Packag Shelf Life 9:69-78

21. Arfat YA, Ahmed J, Ejaz M, Mullah M (2018) Polylactide/ graphene oxide nanosheets/clove essential oil composite films for potential food packaging applications. Int J Biol Macromol 107:194-203

22. Mulla M, Ahmed J, Al-Attar H, Castro-Aguirre E, Arfat YA, Auras R (2017) Antimicrobial efficacy of clove essential oil infused into chemically modified LLDPE film for chicken meat packaging. Food Cont 73:663-671

23. Ahmed J, Mulla M, Arfat YA, Bher A, Jacob H, Auras R (2018) Compression molded LLDPE films loaded with bimetallic (Ag$\mathrm{Cu})$ nanoparticles and cinnamon essential oil for chicken meat packaging applications. LWT 93:329-338

24. Piñeros-Hernandez D, Medina-Jaramillo C, López-Córdoba A, Goyanes S (2017) Edible cassava starch films carrying rosemary antioxidant extracts for potential use as active food packaging. Food Hydrocoll 63:488-495

25. Hosseini SF, Rezaei M, Zandi M, Farahmandghavi F (2015) Biobased composite edible films containing Origanum vulgare L. essential oil. Ind Crop Prod 67:403-413

26. Correa-Pacheco ZN, Black-Solís JD, Ortega-Gudiño P, Sabino-Gutiérrez MA, Benítez-Jiménez JJ, Barajas-Cervantes A, 
Hurtado-Colmenares LB (2020) Preparation and characterization of bio-based PLA/PBAT and cinnamon essential oil polymer fibers and life-cycle assessment from hydrolytic degradation. Polymers 12(1):38

27. Moradi M, Tajik H, Rohani SMR, Oromiehie AR, Malekinejad H, Aliakbarlu J, Hadian M (2012) Characterization of antioxidant chitosan film incorporated with Zataria multiflora Boiss essential oil and grape seed extract. Lwt-Food Sci Technol 46(2):477-484

28. Atarés L, Chiralt A (2016) Essential oils as additives in biodegradable films and coatings for active food packaging. Trends Food Sci Tech 48:51-62

29. Ramirez PZ, Sanchez MY (2019) Universidad de Santiago de Chile, Degradable packaging film for fruit and vegetables: U.S. Patent Application 16/065, 428

30. Vogler EA (1998) Structure and reactivity of water at biomaterial surfaces. Adv Colloid Interfac 74(1-3):69-117

31. Atef M, Rezaei M, Behrooz R (2015) Characterization of physical, mechanical, and antibacterial properties of agar-cellulose bionanocomposite films incorporated with savory essential oil. Food Hydrocoll 45:150-157

32. Ojagh SM, Rezaei M, Razavi SH, Hosseini SMH (2010) Development and evaluation of a novel biodegradable film made from chitosan and cinnamon essential oil with low affinity toward water. Food Chem 122(1):161-166
33. Nuñez L, D’Aquino M (2012) Microbicide activity of clove essential oil (Eugenia caryophyllata). Braz J Microbiol 43(4):1255-1260

34. Kim YG, Lee H, Gwon G, Kim SI, Park JG, Lee J (2016) Essential oils and eugenols inhibit biofilm formation and the virulence of Escherichia coli O157: H7. Sci Rep 6(1):1-11

35. Khalil AA, Rahman U, Khan MR, Sahar A, Mehmood T, Khan M (2017) Essential oil eugenol: sources, extraction techniques and nutraceutical perspectives. RSC Adv 7(52):32669-32681

36. Kashiri M, Cerisuelo JP, Domínguez I, López-Carballo G, MurielGallet V, Gavara R, Hernández-Muñoz P (2017) Zein films and coatings as carriers and release systems of Zataria multiflora Boiss. essential oil for antimicrobial food packaging. Food Hydrocoll 70:260-268

37. Muriel-Galet V, Cerisuelo JP, López-Carballo G, Lara M, Gavara R, Hernández-Muñoz P (2012) Development of antimicrobial films for microbiological control of packaged salad. Int J Food Microbiol 157(2):195-201

Publisher's Note Springer Nature remains neutral with regard to jurisdictional claims in published maps and institutional affiliations. 